\title{
Educación, Valores, Tecnología y Música. Hacia un modelo inclusivo que apueste por la igualdad y las relaciones interpersonales ${ }^{1}$
}

\author{
Isabel Rodrigo-Martín²; Luis Rodrigo-Martín³; Luis Mañas-Viniegra ${ }^{4}$
}

Recibido: 18 de abril de 2019 / Aceptado: 30 de septiembre de 2019

Resumen. Este trabajo parte de la reflexión teórica sobre la necesidad de un cambio en el sistema educativo que apueste por la inclusión, en el que se contemple la igualdad y desigualdad, las tecnologías y el factor relacional, y que ponga en funcionamiento metodologías que permitan dar respuesta a las diferentes necesidades de una población heterogénea. Desde este planteamiento, se formulan unos objetivos dirigidos a conseguir un modelo inclusivo que contemple los valores, las tecnologías y las relaciones interpersonales y se define una metodología teórica, actitudinal y experimental. Para ello, se realiza un proyecto educativo experimental en Educación Primaria que aborda el uso de las tecnologías de la información y los valores sociales. Tomando como eje vertebrador la música, se diseñan todas las actividades con la finalidad de mejorar el clima del aula y centro, así como el respeto y valoración de la diversidad asociada a nacionalidades, minorías, diversidad funcional... entre el alumnado. La evaluación del proyecto ofrece resultados cualitativos y cuantitativos satisfactorios, tanto en la adquisición de contenidos teóricos como en los procedimientos, valores y normas sociales, lo que permite concluir sobre la necesidad de establecer un modelo de Educación inclusiva donde tenga cabida todo el alumnado.

Palabras clave: Educación inclusiva; igualdad; diferencias; tecnología; factor relacional; Educación Primaria.

\section{[en] Education, Values, Technology and Music. Aiming for an inclusive model committed to equality and interpersonal relations}

\begin{abstract}
This work is based on theoretical reflections regarding the need for a change in the educational system to one that is committed to inclusion, that considers equality and inequality, technologies and the relational factor, and that implements methodologies that can provide a response for a heterogeneous population. From this point of view, objectives have been set to achieve an inclusive model that includes values, technology, and interpersonal relations, in addition to establishing a theoretical, attitudinal and experimental methodology. To this end, a pilot educational project is being carried out in Primary Schools that deals with the use of information technologies and social values. With music as the backbone of the programme, all of the activities are designed with the aim of improving the atmosphere of the classroom and the school, as well as to promote the respect and appreciation of differences: nationalities, minorities, disabilities, etc., among students. Assessment of the project offers adequate qualitative and quantitative results, both in the acquisition of conceptual content as well as in procedures, values and social standards, which allow us to make a conclusion regarding the need to establish an inclusive educational model into which all students can be integrated.
\end{abstract}

Keywords: Inclusive education; equality; differences; technology; relational factor; Primary Education.

Sumario. 1. Introducción. 1.1. Las nostalgias del pasado. 1.2. Los desafíos del futuro. 1.3. Los retos del presente. Nuevos horizontes del conocimiento. 1.4. La inclusión a través de la Educación Musical. 2. Metodología. 3. Proyecto para la prevención y detección del racismo, la xenofobia y formas conexas de intolerancia en las aulas. La igualdad y la diferencia en el contexto escolar. 3.1. Normativa. 3.2. Ejecución del proyecto: Todos diferentes, todos iguales. 3.3. Resultados. Evaluación del proyecto. 3.3.1. Profesorado. 3.3.2. Alumnado. 4. Discusión y conclusiones. 5. Referencias bibliográficas.

\footnotetext{
Investigación financiada por el Proyecto de Innovación PID-140 de la Universidad de Valladolid denominado Publicidad Social y Aprendizaje Servicio. Una experiencia compartida entre el alumnado universitario y el de Educación Primaria para la adquisición de una conciencia personal, social y ambiental para el progreso social.

Universidad de Valladolid (España)

E-mail: isabel.rodrigo@uva.es

Universidad de Valladolid (España)

E-mail: luis.rodrigo@uva.es

4 Universidad Complutense de Madrid (España)

E-mail: lmanas@ucm.es
}

Rev. electrón. complut. inves. educ. music. 17, 2020: 33-47 
Cómo citar: Rodrigo-Martín, I., Rodrigo-Martín, L. y Mañas-Viniegra L. (2020). Educación, Valores, Tecnología y Música. Hacia un modelo inclusivo que apueste por la igualdad y las relaciones interpersonales. Revista Electrónica Complutense de Investigación en Educación Musical, 17, 33-47.

\section{Introducción}

Las sociedades están experimentando numerosas y profundas transformaciones en la forma de organizarse, de relacionarse y de recibir y compartir información. Esto exige nuevos modelos educativos que favorezcan el desarrollo de las competencias que las sociedades y las economías necesitan en la actualidad y en su proyección de futuro. Por tanto, la Educación debe ir más allá de la mera adquisición de contenidos curriculares para centrarse en los entornos creativos de aprendizaje (Loi y Burrow, 2006; Loi y Dillon, 2006; Loi, 2007; Elisondo, Donol y Rinaudo, 2009 , 2012), en las formas de relacionarse entre iguales en centros educativos y en contextos formales (Garrido-Lora, Busquet-Duran y Munté-Ramos, 2016), en el uso de las tecnologías y en las nuevas maneras de aprender (Winocur, 2007; Vargas, 2010) que propicien en el alumnado el desarrollo de sus competencias y se consiga una mayor justicia, equidad social y solidaridad mundial, especialmente en la competencia de conciencia y expresiones culturales, así como en las sociales y cívicas.

Ejemplos de todo ello los encontramos en autores como Bauman (1991; 1998; 2016), Aranda, Marta-Lazo y Gabelas (2012), Marta-Lazo y Gabelas (2016) o Mora (2017), entre otros, quienes ponen de manifiesto temas como la felicidad (de-Azcárate, 1873, 1960; Kant, 1973; Csikszentmihalyi, 1997; Nietzsche, 2007), la igualdad (Bisquerra, 2009; Valcarce-Fernández, 2011), la emoción (Moliné, 1995; Timoneda, 1999; Ledoux, 1999), la Neuroeducación (Jensen, 2004; Spitzer, 2005; Forés y Ligioiz, 2009; Blakemore y Frith, 2011; Mora, 2017) y el factor relacional (Marta-Lazo y Gabelas, 2016), aportando vías para ir adecuando la Educación a las exigencias de las sociedades actuales.

Las sociedades actuales están cada vez más conectadas, pero esto no ha conseguido erradicar la intolerancia, la desigualdad y los conflictos:

Una de las características que definen hoy el desarrollo es la aparición y expansión del mundo de la cibernética, con el estímulo que representan el aumento espectacular de la conectividad por Internet y la generalización de los dispositivos móviles. Vivimos en un mundo conectado. Se estima que el 40\% de la población mundial usa en la actualidad internet, y esta cifra no para de aumentar a un ritmo extraordinario (UNESCO, 2015, p. 26).

Surgen nuevos centros y mecanismos de poder, pero las desigualdades siguen existiendo y, lo que es más preocupante, se han agravado. Las posibilidades de un desarrollo sostenible e inclusivo (Power, 1997) son muy amplias, pero las dificultades, frecuentes y complejas (UNESCO, 2014).

La Educación se convierte en una fuerza transformadora para hacer accesibles los derechos humanos, alcanzar un desarrollo digno, erradicar la pobreza, lograr la sostenibilidad y construir un futuro mejor para todos basado en la igualdad de derechos y oportunidades, la justicia social, el respeto de la diversidad cultural como fuente de riqueza, la solidaridad y la responsabilidad socioeconómica compartida; aspiraciones esenciales de nuestra humanidad.

El enfoque inclusivo reconoce y valora las diferencias individuales y las concibe como una fuente de enriquecimiento y de mejora de la calidad educativa. En el proceso de enseñanza-aprendizaje estas diferencias se hacen aún más presentes; todos los alumnos tienen unas necesidades educativas comunes, que son compartidas por la mayoría, unas necesidades propias, individuales, y dentro de éstas, algunas que pueden ser especiales, que requieren poner en marcha una serie de ayudas, recursos y medidas pedagógicas especiales o de carácter extraordinario, distintas de las que requieren la mayoría de los alumnos (Duk, 2007).

Por estos motivos, se hace necesario volver a replantear la Educación de una manera ambiciosa y profunda para tratar de dar respuesta a las necesidades de un mundo en continuo cambio. Hay que dialogar y debatir sobre un nuevo modelo de Educación en el mundo actual, repasando el pasado y planteando los desafíos del futuro.

\subsection{Las nostalgias del pasado}

Es de interés a la hora de plantear un nuevo modelo de Educación que sean revisados diferentes informes realizados por expertos que ayuden a entender la función de la Educación en estas sociedades emergentes en función de la Educación en la sociedad actual de cualquier país del mundo. Así, contamos en primer lugar con el Informe Faure de 1972 (Elfert, 2015), que establecía las dos nociones interrelacionadas de sociedad de aprendizaje y educación permanente en una época en que los sistemas tradicionales de Educación eran objeto de fuertes críticas. Este informe afirmaba que, pese a que se aceleraban el progreso tecnológico y el cambio social, era inconcebible que la Educación escolar pudiera servir a una persona a lo largo de toda su vida, es decir, que le preparara para vivir en sociedad. Aunque la escuela seguía siendo el medio esencial para transmitir los conocimientos reglados y organizados, se hacía 
necesario completar esta Educación formal con otros aspectos de la vida social: las instituciones sociales, el entorno laboral, el ocio y los medios de comunicación. El informe defendía el derecho y la necesidad de cada individuo de aprender para su propio desarrollo integral: personal, social, económico, político y cultural. También sostenía que la Educación permanente debe ser el punto de partida de las políticas educativas, tanto en los países en vías desarrollo como en los desarrollados (Medel-Añonuevo, Oshako y Mauch, 2001).

En segundo lugar, el Informe Delors de 1996 (Tawil y Cougoureux, 2013) proponía una visión integrada de la Educación a partir de dos conceptos esenciales: aprender a lo largo de toda la vida y los cuatro pilares de la Educación: aprender a conocer, a hacer, a ser y a vivir juntos. No era en sí un modelo nuevo para la reforma de la Educación, sino más bien un documento base para pensar, reflexionar y debatir sobre las opciones al formular las políticas educativas. En el informe se argumenta que las opciones educativas estaban determinadas por el tipo de sociedad en que se desea vivir. Más allá de la funcionalidad inmediata de la Educación, consideraba que la formación de la persona completa era parte esencial de la finalidad de la Educación (Power, 1997).

No hay ninguna duda de que los informes Faure (Elfert, 2015) y Delors (Tawil y Cougoureux, 2013) han inspirado todas las políticas educativas de todo el mundo, pero es preciso reconocer en la actualidad que el contexto mundial ha experimentado una transformación considerable en su panorama intelectual y material desde la década de 1970 y de nuevo a partir de 1990. Este inicio del siglo XXI representa una nueva coyuntura histórica: trae consigo diversos desafíos y nuevas oportunidades para el aprendizaje y el desarrollo humano. Estamos iniciando una fase histórica nueva, caracterizada por la interconexión y la interdependencia -impulsada por la irrupción de las redes sociales-así como por nuevos niveles de complejidad, inseguridad y tensiones en todas las esferas de la sociedad.

\subsection{Los desafíos del futuro}

El Informe Delors ya señalaba diferentes tensiones generadas por el cambio tecnológico, económico y social, definidas de la siguiente manera:

entre lo mundial y lo local, lo universal y lo particular; la tradición y la modernidad; lo espiritual y lo material; las consideraciones a largo y a corto plazo; la necesidad de competir y el ideal de la igualdad de oportunidades; y la expansión del conocimiento y nuestra capacidad para asimilarlo (UNESCO, 2015, p. 20).

Estas siete tensiones sirven como puntos de inflexión para conocer la evolución y los cambios sociales que están surgiendo en estos últimos años. Algunas de ellas se encuentran en auge con la aparición de otras más recientes, entre ellas, modelos de crecimiento económico caracterizados por una vulnerabilidad creciente, una desigualdad en aumento, un mayor estrés ecológico y un aumento significativo de la intolerancia y la violencia. Aunque existen progresos en derechos humanos, la aplicación de las normas sigue siendo un desafío. Un gran desafío al que se enfrenta la Educación para ajustarse a esas tensiones y encontrar las vías para el progreso y la convivencia pacífica y democrática.

\subsection{Los retos del presente. Nuevos horizontes del conocimiento}

Desde el comienzo del siglo XX se han observado avances significativos en el fomento del derecho a la Educación, en parte por los tratados registrados en los marcos de la Educación Para Todos (EPT) y en los Objetivos de Desarrollo del Milenio (ODM), que derivaron posteriormente en los Objetivos de Desarrollo Sostenible (ODS) y la Agenda 2030. Estos progresos se aprecian en la mejora de los índices de matrícula escolar, la disminución en el número de niños no escolarizados, el incremento de los índices de alfabetización, en especial entre los jóvenes, y en la disminución de las diferencias de género a nivel mundial, tanto en lo referido a la matrícula escolar como a la alfabetización de adultos (UNESCO, 2011).

Pese a esos progresos, se ha incumplido la promesa que los gobiernos y los asociados internacionales del desarrollo realizaron en 1990 de atender las necesidades básicas de aprendizaje de niños, jóvenes y adultos. Casi 60 millones de niños y 70 millones de adolescentes en todo el mundo todavía carecen de acceso a una Educación básica efectiva. En 2011, casi 775 millones de adultos continuaban estando considerados como insuficientemente alfabetizados (UNESCO, 2011). Incluso entre los que tienen acceso a la Educación básica formal, se constata que el abandono prematuro de la escuela y una educación de baja calidad contribuyen a la falta de adquisición de las aptitudes básicas, pese a que la calidad de la Educación y la adecuación del aprendizaje siguen siendo preocupaciones esenciales. Al menos 250 millones de niños no saben aún leer, escribir o sumar adecuadamente, incluso después de cuatro años como mínimo asistiendo a la escuela (UNESCO, 2011).

Persisten, además, desigualdades notables entre países y los promedios nacionales de muchos de ellos encubren elevadas desigualdades en los logros alcanzados por la Educación básica (UNESCO, 2014a). Ciertos factores tradicionales de marginación en la Educación, como el género y la residencia urbana o rural, siguen sumándose a otros factores como los ingresos, la lengua, la condición de minoría y la discapacidad para producir desventajas que se refuerzan recíprocamente, en especial en los países con bajos ingresos o afectados por conflictos (UNESCO, 2014a). 
La Educación es el elemento clave para dar respuesta a la igualdad y la diferencia, su papel es imprescindible para que el alumnado adquiera los conocimientos, competencias, habilidades, actitudes, competencias y valores necesarios para dar forma a un futuro de progreso. Educar sobre igualdad y diferencia va más allá de los contenidos curriculares de las Ciencias Sociales y supera el ámbito del aula. Afecta a todos los componentes del sistema educativo, es transversal al currículo y lleva consigo un modelo de aprendizaje experiencial que dura toda la vida. Además, se proponen metodologías de aprendizaje para desarrollar el pensamiento crítico, habilidades para la resolución de problemas y competencias para crear nuevos ambientes cooperativos y creativos. La premisa de una escuela para todos conduce a una escuela inclusiva.

Los nuevos enfoques y políticas educativas, tanto en el ámbito internacional y nacional, abogan por la constitución o transformación de las escuelas en las que todos los niños y niñas aprendan juntos en sistemas educativos que garanticen el desarrollo de las capacidades esenciales para la participación e integración social (Fernández, 2003, p. 4).

La desigualdad parece difícil de erradicar, pues siempre ha existido -"Las migraciones masivas no tienen nada de fenómeno novedoso: han acompañado a la modernidad desde su principio mismo" (Bauman, 2016)-. Sin embargo, puede decidirse cómo manejarla y tratarla desde el sistema educativo para conseguir la igualdad de oportunidades (Aparicio y Tornos, 2012).

La desigualdad, según Bauman, está fuera de todo tipo de control, y recurre a la Educación para fomentar y recuperar el diálogo para poder luchar contra esa desigualdad. Una de las preocupaciones de este sociólogo es la búsqueda de la felicidad, reto de los seres humanos, desde siempre, pero en esta sociedad marcada por el consumo se acaba pensando que todas las ideas de felicidad se pueden comprar en una tienda y se olvidan otras opciones para ser felices, como el trabajo conjunto, la meditación o el estudio. Hay que tener presente que la desigualdad está fuera de todo control y la Educación debe controlar la desigualdad y proporcionar los medios para buscar el bienestar individual y social.

De la felicidad también se ocupa la Neuropsicología y la Neuroeducación, siendo la igualdad y la felicidad valores a alcanzar: "el ser humano solo puede experimentar parpadeos de felicidad. Y es con estos, en esos cortos espacios de tiempo, que asoma el equilibrio, la generosidad, el bienestar y el altruismo. Esa es la felicidad humana” (Mora, 2017, p. 93).

Es necesario también contemplar el entorno tecnológico en el que estamos inmersos y manejar los riesgos del uso de las tecnologías, que en muchos casos aíslan al alumnado y lo incapacitan para un desenvolvimiento correcto en la realidad social. En este sentido, cabe destacar la reivindicación del factor relacional, con su doble componente, uno dirigido a las relaciones humanas y otro a los riesgos del uso indebido de las tecnologías actuales: "tiene una doble dimensión: la R competencial, basada en la capacidad de crear y mantener vínculos sociales y la $\mathrm{R}$ de riesgos, derivados de su uso indebido" (Marta-Lazo y Gabelas, 2016, p. 95). El uso de las TIC en la Educación debe ser consciente de este factor fundamental en el desarrollo integral del alumnado.

\subsection{La inclusión a través de la Educación Musical}

Las diferencias han participado en los últimos tiempos de nuevas políticas inclusivas a través de la Educación Musical como eje vertebrador de la inclusión. La literatura científica ha puesto de manifiesto que las habilidades aprendidas a través de la música por estudiantes con diversidad funcional, y principalmente intelectual, son aplicables a nuevas situaciones, especialmente sociales (Jellison y Draper, 2015). Además, existen ejemplos de experiencias que muestran cómo la aplicación educativa de la música a un entorno pluricultural, desde una perspectiva intercultural, fomenta el respeto y la tolerancia, así como la construcción de espacios comunes de inclusión en el aula (Aguirre-De-Mena y De-Mena, 1992; Gainza y Vivanco, 1996; Bernal-Vázquez, 2003; Cuevas-Romero, 2014; Aparicio-Gervás y León-Guerrero, 2018).

Junto al impacto beneficioso de la intervención musical en el desarrollo de los niños (Dumont, Syurina, Feron y Van-Hooren, 2017), las iniciativas para una Educación inclusiva a través de la música son cada vez más frecuentes en todo el mundo, como consecuencia de un carácter en sí inclusivo que permite que todos los individuos puedan ser musicales (Ruddock, 2018). En Suecia, estudiantes con diversidad intelectual interactuaron con estudiantes de Educación Musical para elaborar lecciones musicales, ayudando en la construcción de su identidad, a pesar del rol direccional ejercido por el profesorado (Nilsson, 2015). La inclusión social y el apoyo en la construcción de la identidad no puede olvidar su aportación emocional en la alegría que brinda a los niños (Niland, 2017). La importancia del empoderamiento o de la ausencia del profesorado en el proceso inclusivo mediante la música también se ha puesto de manifiesto en Colombia con estudiantes con diversidad sensorial (Romero-Hernández y Urrego-González, 2016).

Lamentablemente, no en todos los países han sido positivas estas experiencias. En Hong Kong, por ejemplo, habiendo transcurrido poco más de una década desde la inclusión de estudiantes con necesidades educativas especiales en las aulas sin fomentar la formación del profesorado de música sobre diversidad ha provocado una exclusión efectiva (Wong y Chik, 2016). Por ello, es necesario un activismo docente que se anticipe a las necesidades futuras y los cambios en las políticas educativas (Laes y Schmidt, 2016), que en España han propiciado un declive de la 
Educación Musical en las escuelas (Peñalba, 2017), con diferencias educativas significativas en función del territorio (Casanova-López y Serrano-Pastor, 2018).

Los participantes que no fueron incluidos en el colectivo que la legislación establece como estudiantes con medidas de atención educativa especiales reconocen en este tipo de iniciativas inclusivas basadas en la Educación Musical, a pesar de la aportación positiva de estos programas, que es necesario continuar derribando barreras para una inclusión más amplia (Rickson y Warren, 2018).

\section{Metodología}

El objetivo de esta investigación es implantar un proyecto educativo en el que, utilizando las tecnologías educativas y la música como hilo conductor, se aborden los valores de igualdad y diferencia que dan sentido a una Escuela que apueste por la inclusión.

Se establecen los siguientes objetivos específicos:

- Reflexionar sobre la necesidad de un cambio en el modelo educativo tradicional que apueste por la inclusión.

- Valorar las relaciones interpersonales como eje central en el desarrollo del alumnado.

- Identificar la desigualdad como una realidad social y la necesidad de dar respuestas efectivas desde la institución escolar.

- Conocer mejor los valores sociales, prestando especial interés a la igualdad y la diferencia como fuente de riqueza.

- Contemplar y prestar una atención primordial al factor relacional en este contexto actual regido por la tecnología y el individualismo.

- Redescubrir la música, como eje transversal para la realización de proyectos educativos que trabajen en favor de la inclusión.

La metodología aplicada se estructura en tres fases diferenciadas (véase tabla 1), pero complementarias entre sí. En la primera fase, se aborda un estudio teórico, conceptual y descriptivo en el que se parte del estado de la cuestión en el que se encuentra la Educación en la actualidad y del que se extraen los conceptos que van a ser objeto de estudio y que se consideran claves en el nuevo modelo de Educación propuesto. Estos conceptos son: escuela inclusiva, factor relacional, tecnología y, dentro de los valores sociales, la igualdad y la diferencia.

En la segunda fase, experimental, es donde se plantea un proyecto educativo en el que, utilizando las tecnologías educativas y la música como hilo conductor, se abordan los valores de igualdad y diferencia que dan sentido a una Escuela que apueste por la inclusión. Se otorga especial importancia a la música para reivindicar su papel, ya que la LOMCE no lo reconoce, a pesar de establecer una competencia básica de Conciencia y Expresiones Culturales, y porque el aprendizaje y la adquisición de valores mediante la música es una forma muy motivadora para el alumnado de estas edades.

En último lugar, se ejecuta una fase de evaluación de resultados y se extraen conclusiones finales de los datos obtenidos en el estudio.

Tabla 1. Fases del Proyecto educativo.

\begin{tabular}{|c|c|c|}
\hline Fase & Estudio & Tarea \\
\hline $1^{\mathrm{a}}$ & $\begin{array}{l}\text { Teórico, conceptual y des- } \\
\text { criptivo. }\end{array}$ & $\begin{array}{l}\text { Valores sociales: } \\
\text { - Igualdad y Diferencia. } \\
\text { Factor relacional. } \\
\text { Tecnologías Educativas. }\end{array}$ \\
\hline $2^{\mathrm{a}}$ & Experimental. & $\begin{array}{l}\text { Proyecto educativo: } \\
\text { - Objetivos. } \\
\text { - Competencias. } \\
\text { - Actividades. }\end{array}$ \\
\hline $3^{\mathrm{a}}$ & Estadístico, descriptivo. & $\begin{array}{l}\text { Tratamiento de los datos. } \\
\text { Evaluación de los resultados. } \\
\text { Conclusiones finales. }\end{array}$ \\
\hline
\end{tabular}

Para la evaluación de los resultados, se parte de la elaboración de encuestas con escala Likert realizadas a 54 docentes y 190 estudiantes participantes en el proyecto, que han sido analizados con la utilización del software SPSS v.25. El cuestionario completo fue validado positivamente en todas sus preguntas, obteniendo una consistencia interna total a partir del coeficiente Alfa de Cronbach de 0,746 e incorporando las sugerencias recibidas en el proceso de validación. Posteriormente, se realizan dos focus groups con el profesorado que ha participado en el proyecto, con una composición paritaria de 8 docentes en cada grupo, con el fin de obtener una aproximación cualitativa a la eficacia del proyecto. 
El muestreo seleccionado ha sido incidental, en tanto que era necesario escoger centros escolares -finalmente cuatro en Segovia- en los que existiese la diversidad sobre la que se desea investigar a partir del conocimiento teórico del problema y la participación como expertos del personal de Dirección, orientación, tutoría y profesorado de los centros. Se ha accedido así a una diversidad de culturas en el alumnado, entre las que destacan la española (114 discentes, el 60\% de la muestra), latinoamericana (19), marroquí (15), gitana (23), búlgara (10), china (5) y otras (4). En total, 190 discentes, de los cuales 110 (57,89\% de la muestra) han sido de sexo femenino. La distribución de la muestra de discentes por centros, cursos, edades y sexo ha sido (véase tabla 2) la siguiente:

Tabla 2. Distribución muestral de los estudiantes.

\begin{tabular}{|c|c|c|c|c|c|c|c|c|c|}
\hline \multirow{2}{*}{ Curso (edad) } & \multicolumn{2}{|c|}{$\begin{array}{c}\text { Nueva } \\
\text { Segovia }\end{array}$} & \multicolumn{2}{c|}{$\begin{array}{c}\text { Elena } \\
\text { Fortún }\end{array}$} & \multicolumn{2}{|c|}{ San José } & \multicolumn{2}{|c|}{ Maristas } & \multirow{2}{*}{ Total } \\
\cline { 2 - 9 } & $\mathrm{H}$ & $\mathrm{M}$ & $\mathrm{H}$ & $\mathrm{M}$ & $\mathrm{H}$ & $\mathrm{M}$ & $\mathrm{H}$ & $\mathrm{M}$ & \\
\hline $4^{\circ}(10$ años $)$ & 5 & 10 & 6 & 8 & 5 & 9 & 6 & 12 & 61 \\
\hline $5^{\circ}(11$ años $)$ & 6 & 8 & 7 & 7 & 8 & 7 & 6 & 11 & 60 \\
\hline $6^{\circ}(12$ años $)$ & 6 & 11 & 10 & 8 & 7 & 9 & 8 & 10 & 69 \\
\hline Total & 17 & 29 & 23 & 23 & 20 & 25 & 20 & 33 & 190 \\
\hline
\end{tabular}

Los 54 docentes participantes han sido los asociados a los centros seleccionados en la muestra, con la siguiente distribución: equipo directivo (8), orientadores (4), tutores (12), especialistas en Música (6) y otros especialistas (24).

\section{Proyecto para la prevención y detección del racismo, la xenofobia y formas conexas de intolerancia en las aulas. La igualdad y la diferencia en el contexto escolar}

La necesidad de plantear una correcta Educación en valores subyacente en la literatura científica para formar ciudadanos que puedan transformar la sociedad y mejorar la calidad de vida de los mismos supuso el inicio de la planificación del proyecto educativo. Esta propuesta tiene como finalidad el desarrollo de valores fundamentales, centrándose el proyecto en los valores de igualdad y diferencia. De este modo, si se consigue esa asunción de que todos tenemos los mismos deberes y derechos, podrá practicarse la solidaridad, la justicia, la libertad, el civismo y combatir todo tipo de violencia. Así, será posible creer en la utopía y en la posibilidad de un mundo mejor, más igualitario y más justo: "La utopía puede ser vista tanto con los ojos progresistas de quienes la consideran un factor ineludible del cambio como con los de quienes la desprecien desde un seguro realismo" (Terrén, 1999, p. 6) y supone "esperanza de la culminación de todos los valores del mismo proceso educativo [...] La utopía es por esencia sede de valores" (Avelino, 1994, p. 12).

El hilo conductor del proyecto educativo ha sido la música, que actúa como base para realizar tareas de sensibilización, conocimiento y realización de actividades. El proyecto, puesto en marcha con el título "Todos diferentes, todos iguales", se enmarca dentro de la legislación vigente, relacionada con la Declaración de los Derechos Humanos y con la legislación que regula el sistema educativo español.

En el proyecto se definen claramente (véase apartado 3.2) los objetivos educativos y las competencias que se quieren desarrollar en el alumnado, así como la propuesta concreta de actividades. El proyecto educativo que se presenta en el centro de Educación Primaria parte de un fuerte anclaje teórico descriptivo y de la normativa mundial, europea, española y regional para que no se vea como una actividad más, sino como elemento aglutinador y fundamental en una Educación inclusiva y comprensiva, en un mundo dominado por la tecnología, que tenga como finalidad el desarrollo integral del alumnado:

La educación inclusiva tiene como propósito prestar una atención educativa que favorezca el máximo desarrollo posible de todo el alumnado y la cohesión de todos los miembros de la comunidad.

[...] La inclusión educativa se guía por los siguientes principios fundamentales:

- La escuela debe educar en el respeto de los Derechos Humanos y, para hacerlo, organizarse y funcionar de acuerdo con los valores y principios democráticos.

- Todos los miembros de la comunidad colaboran para facilitar el crecimiento y desarrollo personal y profesional individual, a la vez que el desarrollo y la cohesión entre los iguales y con los otros miembros de la comunidad.

- La diversidad de todas las personas que componen la comunidad educativa se considera un hecho valioso que contribuye a enriquecer a todo el grupo y favorecer la interdependencia y la cohesión social.

- Se busca la equidad y la excelencia para todo el alumnado y se reconoce su derecho a compartir un entorno educativo común en el que cada persona sea valorada por igual. 
- La atención educativa va dirigida a la mejora del aprendizaje de todo el alumnado, por lo que ha de estar adaptada a las características individuales. La necesidad educativa se produce cuando la oferta educativa no satisface las necesidades individuales.

Consecuentemente, la inclusión implica identificar y minimizar las dificultades de aprendizaje y la participación y maximizar los recursos de atención educativa en ambos procesos (Ministerio de Educación, Cultura y Deporte, s.f.).

\subsection{Normativa}

Como parte del proyecto realizado, se analizó la normativa referente a la Declaración de Derechos Humanos como contexto al que debía ceñirse, de modo que se centró en las siguientes disposiciones:

Tabla 3. Normativa relacionada con la Declaración de Derechos Humanos.

\begin{tabular}{|c|l|l|}
\hline Año & \multicolumn{1}{|c|}{ Resolución / Pacto / Carta } & \multicolumn{1}{c|}{ Información } \\
\hline 1948 & $\begin{array}{l}\text { Declaración Universal de } \\
\text { los Derechos Humanos }\end{array}$ & $\begin{array}{l}\text { Adoptada y proclamada por la Resolución de la Asamblea General 217 } \\
\text { A, de 1948 (DUDH), en su preámbulo considera la libertad, la justicia y } \\
\text { la paz en el mundo como derechos inalienables de la humanidad. El texto } \\
\text { formula 30 artículos. }\end{array}$ \\
\hline 1976 & $\begin{array}{l}\text { Pacto Internacional de los } \\
\text { Derechos Civiles y Políticos } \\
\text { (PIDCP) 16/12 }\end{array}$ & $\begin{array}{l}\text { Con entrada en vigor el 23/03/1976, los estados presentes en este pacto } \\
\text { depositado en Naciones Unidad se comprometen a lo largo de sus 53 artí- } \\
\text { culos a que todos los individuos puedan ejercer sus derechos e impone a } \\
\text { los Estados la obligación de promover el respeto universal y efectivo de los } \\
\text { derechos y las libertades humanas. }\end{array}$ \\
\hline 1976 & $\begin{array}{l}\text { Pacto Internacional de } \\
\text { Derechos Económicos, } \\
\text { Sociales y Culturales (PIDESC) }\end{array}$ & $\begin{array}{l}\text { Este pacto, al igual que en el anterior, intenta asegurar que todos los seres } \\
\text { así como de sus derechos civiles y políticonos. } \\
\text { El texto está formado por 31 artículos, depositado también en los archivos } \\
\text { de Naciones Unidas. }\end{array}$ \\
\hline 2009 & $\begin{array}{l}\text { Promueve que los pueblos de Europa compartan unos valores comunes } \\
\text { para crear una unión más estrecha. } \\
\text { La Unión Europea está fundada sobre los valores universales de la digni- } \\
\text { dad humana, la libertad y la solidaridad y crea un espacio de libertad, se- } \\
\text { guridad y justicia. Esta carta reafirma la protección de estos derechos fun- } \\
\text { damentales en la evolución de la sociedad, el progreso social y los avances } \\
\text { científicos y tecnológicos en siete capítulos: dignidad, libertad, igualdad, } \\
\text { solidaridad, ciudadanía, justicia y otras disposiciones generales. }\end{array}$ \\
\hline $\begin{array}{l}\text { Fundamentales de la } \\
\text { Unión Europea (CDFUE) }\end{array}$
\end{tabular}

En relación a la normativa existente sobre Educación en España, hay que destacar la LOMCE, Ley Orgánica 8/2013, de 9 de diciembre, para la mejora de la calidad educativa. En esta Ley queda reflejado que el funcionamiento del Sistema Educativo Español está guiado por los principios de calidad, cooperación, equidad, libertad de enseñanza, mérito, igualdad de oportunidades, eficiencia en la gestión de recursos públicos, transparencia y rendición de cuentas.

Tabla 4. Normativa relacionada con Educación.

\begin{tabular}{|c|c|l|l|}
\hline Año & \multicolumn{1}{|c|}{ Ley } & \multicolumn{1}{|c|}{ Propuesta educativa } & \multicolumn{1}{c|}{ Valores } \\
\hline 1978 & Constitución & $\begin{array}{l}\text { Programa general de la enseñanza (Art. 27.5). } \\
\text { Ninguna confesión estatal (Art. 16.3). Dere- } \\
\text { cho a la formación religiosa y moral según } \\
\text { convicciones (Art. 27.3) }\end{array}$ & $\begin{array}{l}\text { Derecho a la Educación y Desarrollo pleno de } \\
\text { la personalidad humana (Art. 27). } \\
\text { Principios democráticos: derechos, libertades, } \\
\text { convivencia (Art. 27). }\end{array}$ \\
\hline 1985 & LODE & $\begin{array}{l}\text { Actividad educativa de acuerdo con la Consti- } \\
\text { tución (Art. 2). }\end{array}$ & $\begin{array}{l}\text { La Educación es (preámbulo): fundamento de } \\
\text { progreso, condición de bienestar social y pros- } \\
\text { peridad, soporte de las libertades individuales. }\end{array}$ \\
\hline 1990 & LOGSE & $\begin{array}{l}\text { Contenidos actitudinales en todas las áreas. } \\
\text { Materias: Educación Moral y Cívica trans- } \\
\text { versal (Primaria), Ética (Secundaria), La vida } \\
\text { moral y la reflexión ética, Ciencias Sociales, } \\
\text { Geografía e Historia (Secundaria). }\end{array}$ & $\begin{array}{l}\text { La Educación procura (título preliminar) el } \\
\text { desarrollo de la personalidad; derechos y li- } \\
\text { bertades; igualdad entre hombres y mujeres; } \\
\text { tolerancia y } \\
\text { libertad; respeto, pluralidad lingüística y cul- } \\
\text { tural; participación activa; paz, cooperación y } \\
\text { solidaridad. }\end{array}$ \\
\hline
\end{tabular}




\begin{tabular}{|l|l|l|l|}
\hline 1995 & LOPEG & $\begin{array}{l}\text { Regula la participación educativa en el go- } \\
\text { bierno de los centros y en actividades com- } \\
\text { plementarias y extraescolares, la elaboración } \\
\text { y publicación de su proyecto educativo y la } \\
\text { autonomía en la gestión de recursos. Garantiza } \\
\text { la escolarización con necesidades especiales. }\end{array}$ & $\begin{array}{l}\text { El progreso equilibrado de una sociedad de- } \\
\text { mocrática, su bienestar colectivo y la calidad } \\
\text { de la vida individual de sus ciudadanos son } \\
\text { fruto del desarrollo de la Educación, en sus } \\
\text { distintos niveles (exposición de motivos) }\end{array}$ \\
\hline 2002 & LOCE & $\begin{array}{l}\text { Materias: Sociedad, Cultura y Religión, con } \\
\text { doble opción: confesional / no confesional (de } \\
\text { carácter obligatorio en las diferentes etapas). }\end{array}$ & $\begin{array}{l}\text { Sistema de calidad: equidad para un desarrollo } \\
\text { pleno de la personalidad, principios democrá- } \\
\text { ticos, derechos y libertades, igualdad de géne- } \\
\text { ro, libertad personal, cohesión y solidaridad, } \\
\text { responsabilidad social, participación cívica. }\end{array}$ \\
\hline 2006 & LOE & $\begin{array}{l}\text { Materias: Educación para la Ciudadanía y } \\
\text { DD.HH. (Primaria y Secundaria), Educación } \\
\text { Ético-Cívica (4º Secundaria), Filosofía y Ética } \\
\text { (Bachillerato). }\end{array}$ & $\begin{array}{l}\text { Valores de la Constitución: Derechos y liber- } \\
\text { tades (Art. 2). } \\
\text { Transmisión y práctica de valores (Art. 1): res- } \\
\text { peto y tolerancia, igualdad y libertad, respon- } \\
\text { sabilidad y esfuerzo. }\end{array}$ \\
\hline 2013 & LOMCE & Materias: Valores Sociales y Cívicos. & $\begin{array}{l}\text { Finalidades y valores de las actitudes que los } \\
\text { impulsan. }\end{array}$ \\
\hline
\end{tabular}

También se especifica que en la escuela se deben promover los valores que fomenten la igualdad efectiva entre hombres y mujeres, así como la prevención de la violencia de género, la prevención de conflictos y la resolución pacífica de los mismos.

Tabla 5. Normativa relacionada con los valores en la Educación.

\begin{tabular}{|c|l|}
\hline Año & \multicolumn{1}{c|}{ Orden / Resolución } \\
\hline 2009 & $\begin{array}{l}\text { Resolución de 15 de junio de 2009, sobre los Indicadores de Informes de Convi- } \\
\text { vencia escolar, al ser un tema de gran relevancia para este trabajo. }\end{array}$ \\
\hline 2014 & $\begin{array}{l}\text { Orden EDU/519/2014, de 17 de junio, por la que se establece el currículo y se } \\
\text { regula la implantación, evaluación y desarrollo de la Educación primaria en la } \\
\text { Comunidad de Castilla y León, por ser en esta Comunidad, en Segovia concreta- } \\
\text { mente, donde se han llevado a cabo los proyectos educativos diseñados. En esta } \\
\text { Orden se señala también el área de Valores Sociales y Cívicos, que se concibe } \\
\text { como una de las novedades que contempla la nueva Ley de Educación. }\end{array}$ \\
\hline
\end{tabular}

Al hablar de valores de igualdad y diferencia, no se pueden dejar al margen los Derechos Humanos Universales ni la legislación vigente que regula el sistema educativo español (LOMCE), así como las normas y decretos correspondientes a la Comunidad de Castilla y León, en la que se ha llevado a cabo este proyecto.

\subsection{Ejecución del proyecto: Todos diferentes, todos iguales}

El proyecto fue presentado a los equipos directivos, a los orientadores de los centros y a los tutores donde se iban a llevar a cabo: CEIP Nueva Segovia, centro público, con una población importante de minorías étnicas (aproximadamente el 50\% del alumnado); CEIP San José, centro público con una población importante de inmigrantes; CEIP Elena Fortún, centro público de clase media-baja y Colegio Maristas Nuestra Señora de la Fuencisla, centro religioso concertado con una población de clase media-alta.

Tabla 6. Objetivos, competencias y actividades del Proyecto.

\begin{tabular}{|l|l|l|}
\hline \multicolumn{3}{|c|}{ Datos formales del Proyecto “Todos diferentes, todos iguales” } \\
\hline Centros & $\begin{array}{l}\text { CEIP Nueva Segovia, CEIP Elena Fortún, CEIP San José, Colegio Maristas Nuestra Se- } \\
\text { ñora de la Fuencisla }\end{array}$ \\
\hline Cursos & $4^{\circ}, 5^{\circ}$ y $6^{\circ}$ de Educación Primaria & 54 \\
\hline $\mathrm{N}^{\circ}$ de discentes & 190 & $\mathrm{~N}^{\circ}$ de docentes \\
\hline \multicolumn{2}{|c|}{ Competencias } \\
\hline Respetar las diferencias como fuente de riqueza. & Interacción física y social. \\
\hline Conocer y comprender las diferencias culturales. & Competencia cultural y artística. \\
\hline
\end{tabular}




\begin{tabular}{|l|l|}
\hline Celebrar las diferencias entre personas del mismo entorno. & Interacción física y social. \\
\hline Respetar las otras culturas. & Aprender a aprender. \\
\hline Convivir de forma pacífica y gratificante. & Interacción física y social. \\
\hline Adquirir empatía y capacidad de escuchar a los demás. & Autonomía e iniciativa personal. \\
\hline Prestar ayuda a los demás. & Competencia social y ciudadanía. \\
\hline Aprender a trabajar en equipo. & Aprender a aprender. \\
\hline Valorar las cualidades de los demás. & Autonomía e iniciativa personal. \\
\hline $\begin{array}{l}\text { Conseguir la responsabilidad hacia el trabajo y los deberes } \\
\text { de cada uno. }\end{array}$ & Interacción física y social. \\
\hline Poner en valor y práctica la comprensión y la empatía. & Interacción física y social. \\
\hline $\begin{array}{l}\text { Resolver los conflictos a través del diálogo y no con } \\
\text { violencia. }\end{array}$ & Competencia aprender a aprender. \\
\hline $\begin{array}{l}\text { Adquirir hábitos de convivencia y comunicación como } \\
\text { medio de resolver conflictos. }\end{array}$ & Competencia social y ciudadanía \\
\hline Conocer y apreciar los valores y las normas de convivencia. & Aprender a aprender \\
\hline $\begin{array}{l}\text { Manejar las TIC para el saludo del alumnado en diferentes } \\
\text { idiomas. }\end{array}$ & $\begin{array}{l}\text { Tratamiento de la información y la competencia digital. } \\
\text { Dompetencia social y ciudadanía. } \\
\text { Digital. } \\
\text { Lingüística. }\end{array}$ \\
\hline $\begin{array}{l}\text { Utilizar las TIC teniendo en cuenta la importancia de esta- } \\
\text { blecer de forma gratificante el llamado Factor Relacional }\end{array}$ & $\begin{array}{l}\text { Tratamiento de la información y la competencia digital. } \\
\text { Competencia social y ciudadanía. }\end{array}$ \\
\hline $\begin{array}{l}\text { Entender la publicidad social como una herramienta edu- } \\
\text { cativa al servicio del progreso social }\end{array}$ & Tratamiento de la información y la competencia digital. \\
\hline
\end{tabular}

\section{Actividades}

BLOQUE I

- Seleccionar la canción representativa de los valores a trabajar. Trabajar el lenguaje de la canción separando las palabras positivas de las negativas. Las canciones con las que se han trabajado han sido: Mensajes del agua (Macaco), Somos uno (Axel Abel Pintos), La rumba del emigrante (Javier Moreno), El emigrante (Celtas Cortos), Canción para el inmigrante (Juan Pablo Chávez), Tras los libros (Kiko y Shara), Eres único (Agrupación de Artistas Peruanos), Canción contra el Bullying (Emanero), Campaña de valores (Niña Dioz), Brought up that way (Taylor Swift), Hopeful (Bars y Melody).

- Dinámica en grupo para presentarse y conocer su nacionalidad, su cultura y aspectos relacionados con su cultura y tradiciones:

- Puestos en círculo, tirar una pelota y a quién le toque contestar a:

- Cómo me llamo.

- Dónde he nacido.

- De dónde son mis padres.

- Hablo castellano y...

- Mi país de origen se llama...

- Las fiestas que celebro son...

- Hacer un mural donde estén representados todos los países del alumnado de clase:

- Mapa de países:

- Idioma.

- Forma de gobierno.

- Religión.

- Tradiciones.

- Realizar un marca páginas de cada uno de los países.

- Inventar pareados que favorezcan las relaciones con miembros de otras culturas.

- Utilizar las TIC, para la búsqueda de información de diferentes países, costumbres y tradiciones.

BLOQUE II

- La canción elegida será representada de forma plástica y se realizará la coreografía.

- Utilizar la canción trabajada como himno del curso y se cantará en todas las celebraciones del centro.

BLOQUE III

- Realizar carteles en defensa de los valores trabajados.

- Producción y realización de spots publicitarios sobre la escuela inclusiva y los valores sociales: igualdad y diferencia. 


\subsection{Resultados. Evaluación del proyecto}

La valoración final del proyecto se ha realizado en una triple dimensión:

- Por parte del profesorado, que ha valorado satisfactoriamente el proyecto, agradeciendo la planificación de actividades y los materiales que se les ha proporcionado, aunque también han existido algunas observaciones sobre el tiempo invertido, considerando que se les quitaba de otras actividades de las asignaturas. Estas sugerencias se han recogido por el equipo de orientación y se ha establecido un debate sobre la importancia de unificar el contenido en proyectos de este tipo, donde se puede abarcar el contenido de las diferentes disciplinas.

- El alumnado ha valorado positivamente las actividades programadas. Se ha sentido protagonista del aprendizaje y lo ha relacionado con sus experiencias vitales.

- Tanto por parte del equipo investigador como del equipo de orientación del centro (evaluación cualitativa), se considera que este proyecto ha sido un primer estímulo motivador para seguir programando actividades en las que el estudio y la vivencia de los valores forme parte del currículo oficial, ya que una Educación de calidad debe responder a los conocimientos y a los valores éticos y estéticos, para así poder conseguir los objetivos de la etapa educativa de la Educación Primaria:

- Adquirir habilidades para la prevención pacífica de conflictos, que les permitan desenvolverse con autonomía en el ámbito familiar y doméstico, así como en los grupos sociales con los que se relacionan.

- Conocer, comprender y respetar las diferencias culturales y las diferencias entre las personas, la igualdad de derechos y oportunidades de los hombres y mujeres y la no discriminación de personas con discapacidad (Consejería de Educación-Junta de Castilla y León, 2014, p. 183-184).

Para realizar la evaluación se han elaborado unas hojas registro con diferentes indicadores donde se valoran los ítems. Una vez cotejados los cuestionarios de evaluación, y hecho un recuento de los ítems a evaluar, se han obtenido los siguientes resultados que quedan reflejados en las gráficas que se muestran a continuación.

\subsubsection{Profesorado}

En la valoración obtenida por el profesorado (véase figura 1) en una escala tipo Likert, siendo 5 el valor más alto excelente- y 1, el más bajo -muy deficiente-, la valoración media obtenida ha sido de 4,63 en calidad del proyecto (mediana 5,00; desviación estándar de 0,760); 4,52 en facilidad para realizarlo (mediana 5,00; desviación estándar de 0,795); 4,35 en materiales presentados (mediana 5,00; desviación estándar de 0,974); 4,06 en temporalización adecuada (mediana 4,00; desviación estándar de 1,123) y 4,72 en resultado de las actividades (mediana 5,00; desviación estándar de 0,492 ). La valoración, por tanto, ha sido muy positiva, puesto que el $98,20 \%$ del profesorado participante percibe como excelente o bueno el resultado obtenido.

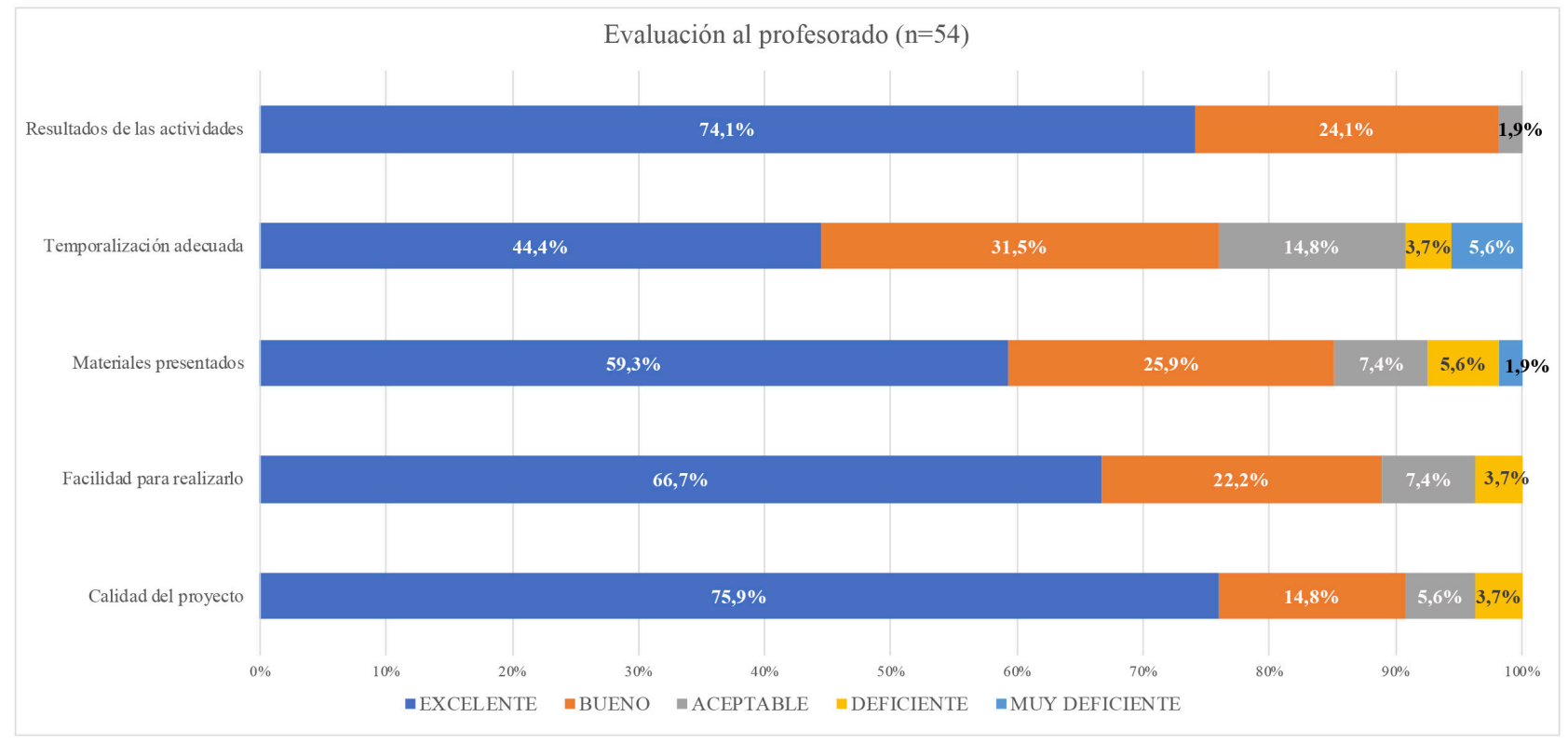

Figura 1. Evaluación del profesorado sobre el proyecto. 
Los focus groups pusieron de manifiesto en una evaluación cualitativa el interés en continuar desarrollando proyectos con esta finalidad: "Hay que comenzar a realizar más prácticas inclusivas en las aulas como este proyecto" (FC-2). A pesar de ello, se reconocen las dificultades asociadas, ya que para poder conseguir una mayor inclusión "se necesita un cambio de actitud en muchos profesores" (FC-1), "más recursos y más formación" (FC-2). También se reconoce que "la inclusión es una utopía difícil de conseguir" (FC-2), pero los buenos resultados que han percibido en la cultura gitana y latina por su facilidad para la integración a través de la música les lleva a afirmar que la inclusión "es un reto a conseguir que requiere ilusión y esfuerzo" (FC-1), aunque ello suponga "horas extra de preparación, dedicación y seguimiento" (FC-1).

\subsubsection{Alumnado}

En la valoración obtenida por el alumnado (véase figura 2) en una escala tipo Likert, siendo 5 el valor más alto -excelente- y 1, el más bajo -muy deficiente-, la valoración media obtenida ha sido de 4,35 en interés por la actividad (mediana 5,00; desviación estándar de 0,918); 4,31 en tiempo para realizarlo (mediana 5,00; desviación estándar de 1,085); 4,34 en materiales utilizados (mediana 4,00; desviación estándar de 0,730); 4,11 en la satisfacción experimentada (mediana. 4,00; desviación estándar de 1,039). La valoración ha sido muy positiva, puesto que el 95,30\% de los participantes ha mostrado un interés positivo por la actividad y al $91,60 \%$, le ha gustado.

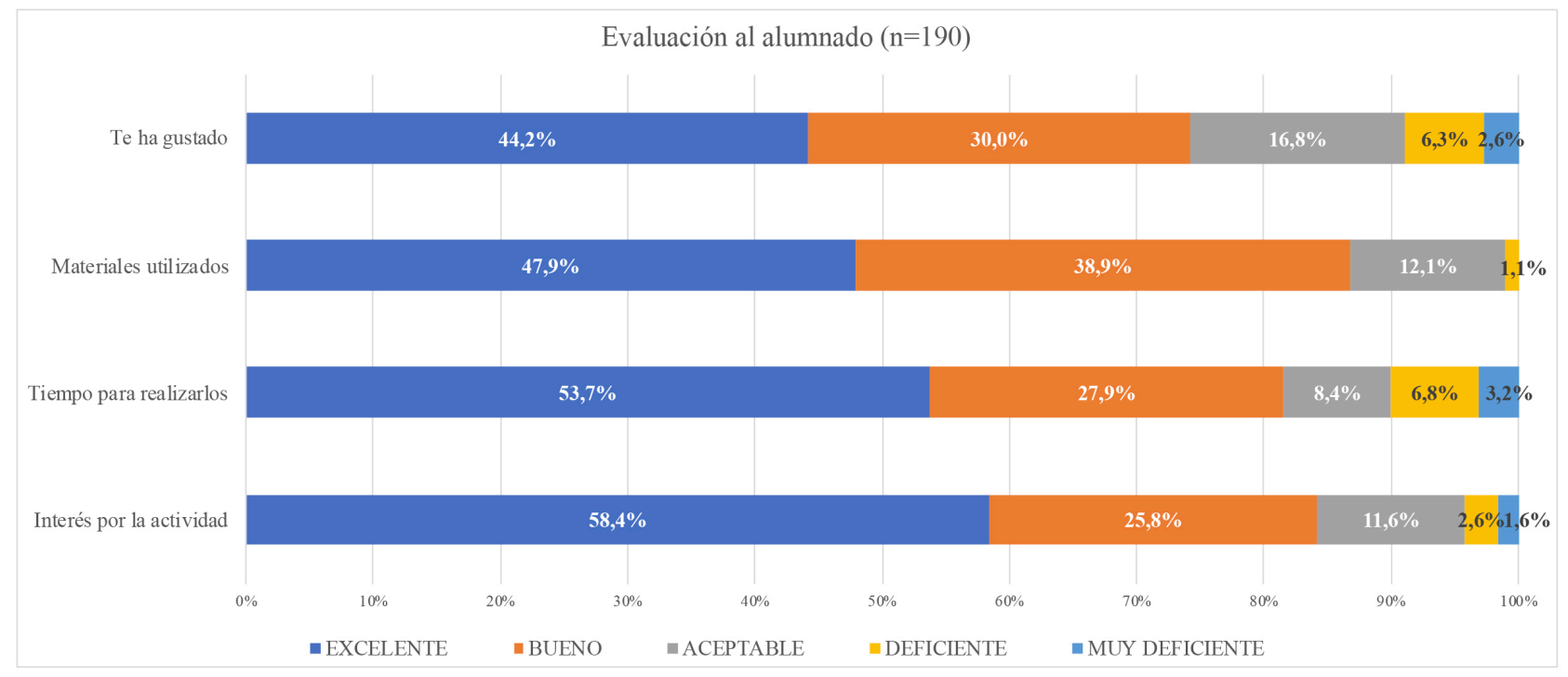

Figura 2. Evaluación del alumnado sobre el proyecto.

En último lugar, se preguntó a los participantes si estarían dispuestos a repetir la experiencia en otros proyectos similares, obteniendo un $76,84 \%$ de respuestas afirmativas, un $8,42 \%$ negativas y el $14,74 \%$ de los participantes, no contestó.

No cumpliéndose una distribución normal en cada variable conforme a la prueba de Kolmogorov-Smirnov -con una significación asintótica bilateral inferior a $0,05-$ y contrastando variables ordinales correspondiente a una escala tipo Likert, se aplica el Test U de Mann-Whitney, cuyo principal resultado en el contraste con la variable sexo es que el sexo femenino ofrece valoraciones superiores en Interés, Tiempo, Materiales y Satisfacción. Sin embargo, solo existen diferencias significativas en la valoración que realizaron ambos grupos sobre la variable Tiempo $(\mathrm{p}=, 028)$.

Se aplicó posteriormente la prueba $\mathrm{H}$ de Kruskal-Wallis al contraste por edades, resultando que las edades más tempranas muestran valoraciones significativamente diferentes con respecto al Tiempo $(p=, 000)$ y a los Materiales $(p=, 000)$, sin que las diferencias en Interés y Satisfacción sean relevantes.

En cuanto al contraste de resultados en las diferentes culturas, basado también en la prueba $\mathrm{H}$ de Kruskal-Wallis, existen diferencias significativas en Interés $(\mathrm{p}=, 000)$, Tiempo $(\mathrm{p}=, 002)$ y Satisfacción $(\mathrm{p}=, 000)$, pero no así en Cultu$\mathrm{ra}(\mathrm{p}=, 385)$. El interés y especialmente la satisfacción (véase figura 3 ) son sustancialmente inferiores en las culturas búlgara y marroquí. 


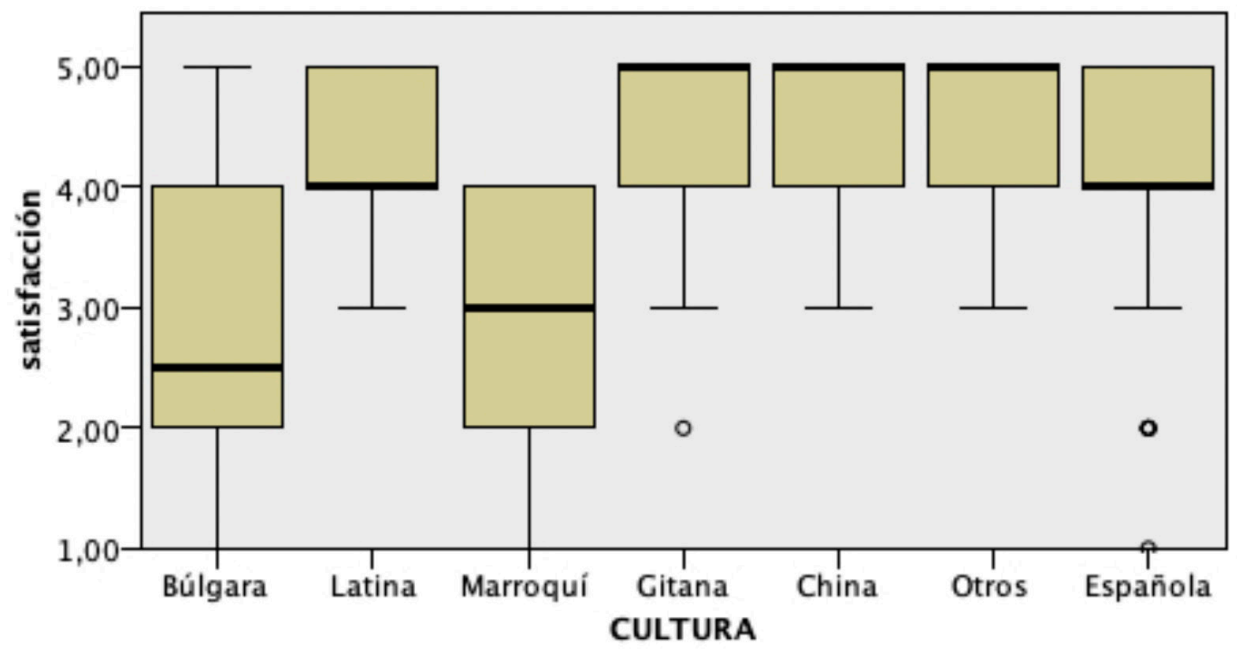

Figura 3. Prueba de Kruskal-Wallis por cultura del alumnado.

En el contraste entre parejas (véase figura 4), es especialmente significativa la inferior valoración de la cultura marroquí frente a la española $(p=, 000)$, la gitana $(p=, 000)$ y la latina $(p=, 006)$, al igual que sucede con la cultura búlgara con respecto a la gitana $(\mathrm{p}=, 009)$ y la española $(\mathrm{p}=, 032)$.

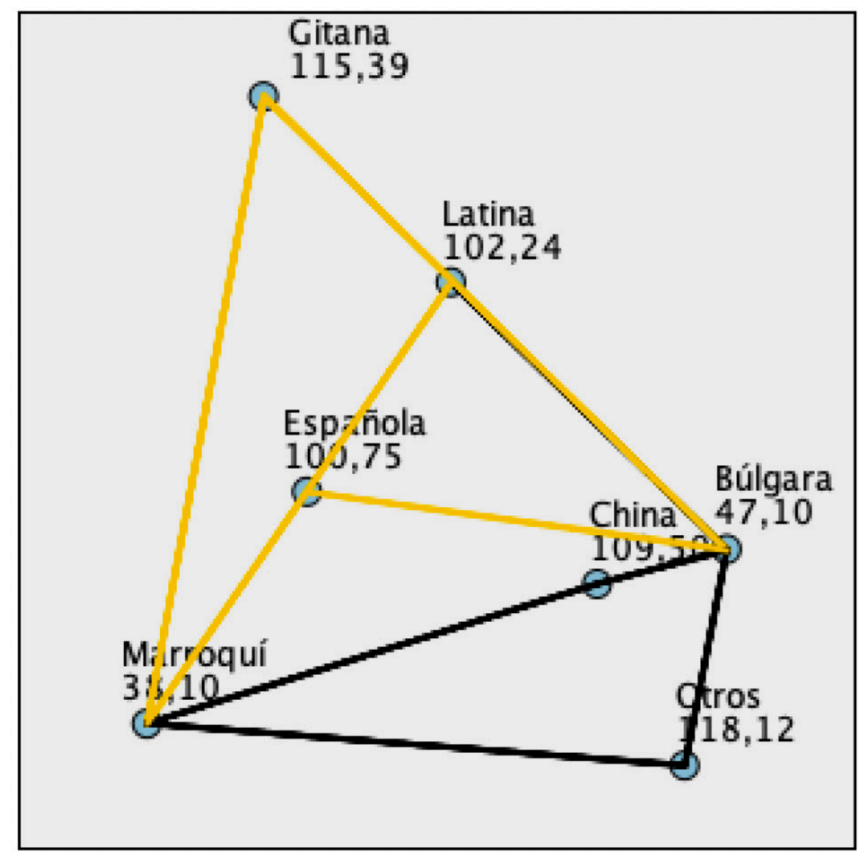

Figura 4. Prueba U de Mann-Withney entre parejas por culturas del alumnado.

\section{Discusión y conclusiones}

El objetivo principal de este presente trabajo ha sido analizar las relaciones existentes entre las conductas violentas que dificultan la convivencia democrática y la necesidad de una Educación en valores que permita el desarrollo integral del alumnado y forme ciudadanos competentes para transformar la sociedad. El enfoque de este trabajo no podía, por tanto, ser otro que el derivado del manejo de las tecnologías educativas, del conocimiento de los valores universales de la convivencia y de las competencias necesarias para proponer modelos educativos que permitan la convivencia pacífica y gratificante, todo ello a partir de la creatividad y la música como base.

En el estudio realizado, se ha pretendido mostrar la importancia de definir claramente los valores a transmitir, destacando la igualdad y la diferencia, las características necesarias que se dan en una sociedad tecnológica y las relaciones humanas para conseguir la convivencia deseada, contando con las necesidades y capacidades del ser humano y definiendo las competencias básicas, señaladas por la Unión Europea y recogidas en la nueva Ley de Educación (LOMCE). 
Así, este estudio, presenta un proyecto educativo que atiende a la diversidad y la Educación inclusiva (Echeita y Cuevas, 2011) y que, tomando como eje vertebral la música, indaga sobre los derechos humanos, la condena de cualquier forma de exclusión y violencia (Díaz-Aguado, 1999) y la apuesta por el uso de las tecnologías educativas (Garrido-Lora, Busquet-Duran y Munté-Ramos, 2016) y la creación musical (Casanova-López y Serrano-Pastor, 2018) como medios de transformación de la sociedad en base a las relaciones entre sus miembros.

La realización de este proyecto permite comprender en su totalidad la importancia de la Educación como transmisora de los valores sociales de igualdad y diferencia y representativa de las actitudes y normas que favorecen las relaciones pacíficas y democráticas. El proyecto educativo ejecutado en varios centros de Educación Infantil y Primaria, a la luz de las valoraciones del profesorado y alumnado implicado, ha permitido comprobar que se ha mejorado el clima de aula y se han potenciado las actitudes de respeto, tolerancia y conductas solidarias.

La asunción de la igualdad y la diferencia como valores fundamentales de los seres humanos permiten la dignificación de la vida humana, el derecho a tener derechos, la equidad, la sensibilidad, el compromiso responsable, el reconocimiento para favorecer las relaciones interpersonales y la mejora del grupo o clase, que se convierte en un contexto creativo que facilita la innovación, la toma de decisiones, la mejora de la comunicación, el aprendizaje y la mejora de los procesos de enseñanza-aprendizaje, así como el reconocimiento de los líderes de la producción y del mantenimiento socio-afectivo del grupo (véase figura 5).

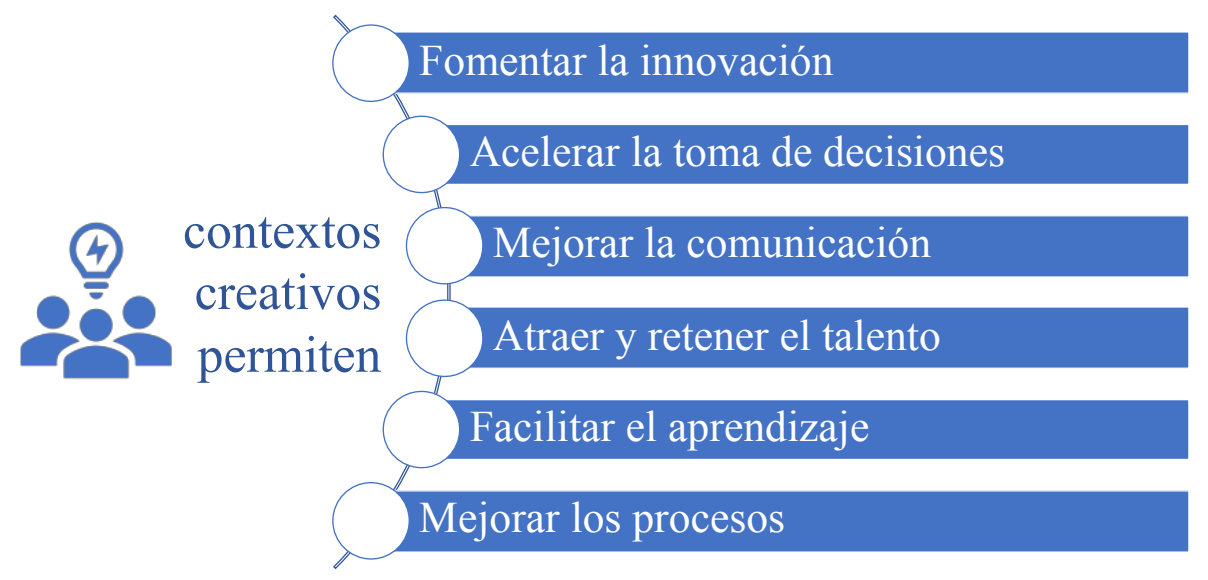

Figura 5. Resultados de los contextos creativos.

El estudio de los valores, tal como fue planteado en el proyecto, con el uso de las tecnologías educativas, la creación musical y la metodología empleada, ha permitido al alumnado tomar conciencia de sí mismos, del papel que desempeñan dentro del grupo, de la importancia de sus opiniones y actitudes, lo que ha posibilitado mejorar su autoestima y reconocer su papel protagonista en el proceso de enseñanza-aprendizaje.

Las actividades planteadas han puesto de manifiesto la necesidad de un buen clima en el aula para conseguir esa convivencia pacífica que permite a los participantes conocer y gestionar sus emociones y sentimientos, así como desarrollar su empatía para darse cuenta de las necesidades de los otros y trabajar por el interés común.

Igualmente, el estudio de los valores ha servido para mejorar las habilidades sociales y tomar conciencia de que estas habilidades pueden adquirirse con el aprendizaje musical. Cabe destacar la importancia que, tanto el profesorado como el alumnado, han concedido a utilizar la música como herramienta educativa de gran valor para conseguir esa motivación inicial, especialmente relevante en todos los procesos de enseñanza-aprendizaje. El éxito de las canciones seleccionadas se ha puesto de manifiesto en las evaluaciones obtenidas.

Ha destacado la capacidad de la música como elemento inclusivo, especialmente en culturas con mayor tradición musical, como la gitana o la latina, que muestran muchos puntos de conexión con la cultura musical española. Resulta coherente, por tanto, que el mayor interés y satisfacción se hayan producido en el alumnado con esta procedencia, en línea con la construcción de espacios comunes de inclusión en el aula a la que aludía la literatura científica (Aguirre-De-Mena y De-Mena, 1992; Gainza y Vivanco, 1996; Bernal-Vázquez, 2003; Cuevas-Romero, 2014; Aparicio-Gervás y León-Guerrero, 2018).

Las diferencias por edad con respecto al Tiempo y los Materiales puestas de manifiesto en los resultados son coherentes con un proceso de enseñanza-aprendizaje progresivo, por lo que en próximos proyectos es recomendable adaptar la dificultad de la actividad a los diferentes tramos de edad.

No se pueden obviar las dificultades mostradas por el profesorado en cuanto al esfuerzo en la preparación y ejecución de las actividades del proyecto, por lo que parecen necesarios programas de impulso por parte de las Administraciones Públicas que faciliten más actividades inclusivas y que no recaigan todos los esfuerzos sobre el personal de los centros educativos, como ha ocurrido históricamente en el sistema educativo español, situación agravada por el declive de la Educación Musical en las escuelas (Peñalba, 2017). Mayores recursos proporcionarán mayores oportunidades para establecer actividades planificadas a lo largo del curso académico y no concentradas en el tiempo como 
en el proyecto actual, que ha sido una de las limitaciones que han manifestado los docentes. Estos recursos también deben ir destinados a una mayor sensibilización por parte del profesorado, que manifiesta off the record su lamento porque siempre sean los mismos los que se impliquen en este tipo de iniciativas. Esta situación está en consonancia con la falta de activismo docente reseñado en el estado de la cuestión (Laes y Schmidt, 2016). Este mayor apoyo permitiría, a su vez, proporcionar materiales más elaborados y más afines al alumnado, incluso composiciones creadas especialmente para una finalidad inclusiva, lo cual repercutiría positivamente en una mejor evaluación en cuanto al interés despertado y la satisfacción experimentada.

En último lugar, es necesario señalar que la consecución de los objetivos planteados ha favorecido el desarrollo de las competencias que se habían reseñado en el diseño del proyecto propuesto.

La humanidad ha iniciado una nueva fase de su historia con un creciente y rápido desarrollo de la ciencia y la tecnología, que ofrecen a la vez posibilidades utópicas y distópicas. Para que puedan beneficiarnos de manera emancipadora, justa y sostenible, es preciso comprender y controlar las oportunidades y los riesgos. Posibilitarlo debería ser la finalidad esencial de la educación y el aprendizaje del siglo XXI (UNESCO, 2015, p. 93).

\section{Referencias bibliográficas}

Aguirre-De-Mena, O. y De-Mena, A. (1992). Educación musical. Manual para el profesorado. Granada: Aljibe.

Aparicio, R. y Tornos, A. (2012). La socialización juvenil de las segundas generaciones de la inmigración: factores, metas, transformaciones identitarias. Madrid: Ministerio de Empleo y Seguridad Social.

Aparicio-Gervás, J. M. y León-Guerrero, M. M. (2018). La música como modelo de inclusión social en espacios educativos con alumnado gitano e inmigrante. Revista Complutense de Educación, 29(4), 1091-1108. doi: 10.5209/RCED.54878

Aranda, D., Marta-Lazo, C. y Gabelas, J. A. (2012). Per què les TRIC i no les TIC. COMeIN, 9. Recuperado de https://bit.ly/ 2Glzn3E

Avelino, J. (1994). Educación, axiología y utopía. Oviedo: Universidad de Oviedo.

De-Azcárate, P. (1873). Obras de Aristóteles. Aristóteles. Política, libro octavo, capítulo II. Causas diversas de las revoluciones. Madrid: Nueva Biblioteca Filosófica.

De-Azcárate, P. (1960). Obras filosóficas. Madrid: Nueva Biblioteca Filosófica.

Bauman, Z. (1991). Modernidad y ambivalencia. Barcelona: Anthropos.

Bauman, Z. (1998). Modernidad y holocausto. Madrid: Sequitur.

Bauman, Z. (2016). Extraños llamando a la puerta. Barcelona: Paidós.

Bernal-Vázquez, J. (2003). Música y creatividad. En A. M. Gervilla y R. Cervantina (Coords.), Creatividad aplicada. Una apuesta de futuro (pp. 841-864). Málaga: Dykinson.

Bisquerra, R. (2009). Psicopedagogía de las emociones. Madrid: Síntesis

Blakemore, S. y Frith, U. (2011). Cómo aprende el cerebro. Las claves para la educación. Barcelona: Ariel.

Casanova-López, O. y Serrano-Pastor, R. M. (2018). La Educación Musical en el actual currículo español. ¿Qué formación recibe el alumnado en la enseñanza Primaria? Revista Electrónica Complutense de Investigación en Educación Musical, 15, 3-17. doi: 10.5209/RECIEM.54844

Csikszentmihalyi, M. (1997). Fluir (Flow): Una psicología de la felicidad. Barcelona: Kairós.

Cuevas-Romero, S. (2014). Enseñar y aprender de la creatividad, en la práctica musical de educación secundaria. En P. Murillo-Estepa (Coord.), Libro de Actas IV Jornadas de Innovación Docente de la Facultad de Ciencias de la Educación "Abriendo caminos para la mejora educativa". Sevilla: Universidad de Sevilla. Recuperado de https://bit.ly/2NF88be

Díaz-Aguado, M. J. (1999). El desarrollo de la tolerancia y la prevención de la violencia desde la educación. En Ministerio de Trabajo e Inmigración (Ed.), Calidad y responsabilidad compartida. Retos del bienestar en el cambio de siglo (pp. 207-222). Madrid: Ministerio de Trabajo e Inmigración.

Duk, C. (2007). Inclusiva. Modelo para evaluar la respuesta de la escuela a la diversidad de necesidades educativas de los estudiantes proyecto FONDEF/COINCYT D04I1313. REICE. Revista Iberoamericana sobre Calidad, Eficacia y Cambio en Educación, 5(5), 188-199. Recuperado de https://bit.ly/2L6Hq9E

Dumont, E., Syurina, E. V., Feron, F. J. M. y Van-Hooren, S. (2017). Music Interventions and Child Development: A Critical Review and Further Directions. Frontiers in Psychology, 8, e1694. doi: 10.3389/fpsyg.2017.01694

Echeita, G. y Cuevas, I. (2011). La educación inclusiva. En E. Martín y T. Mauri (Coords.), Orientación educativa. Atención a la diversidad y educación inclusiva (pp. 11-27). Barcelona: Graó/MEC.

Elfert, M. (2015). UNESCO, the Faure report, the Delors report, and the political utopia of lifelong learning. European Journal of Education, 50(1), 88-100. doi: 10.1111/ejed.12104

Elisondo, R. C., Donol, D. S. y Rinaudo, M. C. (2009). Ocasiones para la creatividad en contextos de educación superior. Red U. Revista de docencia Universitaria, 7(4). doi: 10.4995/redu.2009.6233

Elisondo, R. C., Donol, D. S. y Rinaudo, M. C. (2012). Docentes inesperados y creatividad. Experiencias en contextos de educación superior. Revista Electrónica de Investigación, Docencia y Creatividad, 1. 103-114. Recuperado de https://bit.ly/2YLjD2d

Fernández, A. (2003). Educación inclusiva: enseñar y aprender entre la diversidad. Umbral 2000, 13. Recuperado de https://bit. ly/2LHj45y 
Forés, A. y Ligioiz, M. (2009). Descubrir la neurodidáctica: aprender desde, en y para la vida. Barcelona: UOC.

Gainza, V. H. y Vivanco, P. (1996). Música y educación hoy. Buenos Aires: Lumen.

Garrido-Lora, M., Busquet-Duran, J. y Munté-Ramos, R. A. (2016). De las TIC a las TRIC. Estudio sobre el uso de las TIC y la brecha digital entre adultos y adolescentes en España. Anàlisi. Quaderns de Comunicació i Cultura, 54, 44-57. doi: 10.7238/a. v0i54.2953

Kant, I. (1973). Fundamentación de la metafisica de las costumbres. Madrid: Espasa-Calpe.

Jellison, J. A. y Draper, E. A. (2015). Music Research in Inclusive School Settings: 1975 to 2013. Journal of Research in Music Education, 62(4), 325-331. doi: 10.1177/0022429414554808

Jensen, E. (2004). Cerebro y aprendizaje: competencias y educaciones educativas. Madrid: Narcea.

Laes, T. y Schmidt, P. (2016). Activism within music education: working towards inclusion and policy change in the Finnish music school context. British Journal of Music Education, 33(1), 5-23. doi: 10.1017/S0265051715000224

Ledoux, J. (1999). El cerebro emocional. Barcelona: Planeta.

Loi, D. (2007). Reflective probes, primitive probes, and playful triggers. Ethnographic Praxis in Industry Conference, 1, $233-246$. doi: 10.1111/j.1559-8918.2007.tb00079.x

Loi, D. y Burrows, P. (2006). Magritte and the pea: anomalous artefacts and the contexts they create. Working Papers in Art and Design, 4. Recuperado de https://bit.ly/2XRs2nl

Loi, D. y Dillon, P. (2006). Adaptive educational environments as creative spaces. Cambridge Journal of Education, 36(3), 363-381. doi: 10.1080/03057640600865959

Marta-Lazo, C. y Gabelas, J. A. (2016). Comunicación digital. Un modelo basado en el factor Relacional. Barcelona: UOC.

Medel-Añonuevo, C., Oshako, T. y Mauch, W. (2001). Revisiting lifelong learning for the 21st century. Hamburgo: Instituto de la UNESCO para la Educación.

Ministerio de Educación, Cultura y Deporte (s.f.). Educación inclusiva. Recuperado de https://bit.ly/2Dhbbia

Moliné, M. (1995). La fuerza de la publicidad. Madrid: McGraw-Hill.

Mora, F. (2017). Neuroeducación. Solo se aprende lo que se ama. Madrid: Alianza.

Nietzsche, F. W. (2007). Más allá del bien y del mal (A. Sánchez-Pascual, Trad.). Buenos Aires: Gradifco

Niland, A. (2017). Singing and playing together: A community music group in an early intervention setting. International Journal of Community Music, 10(3), 273-288. doi: 10.1386/ijcm.10.3.273_1

Nilsson, M. H. Z. (2015). Inclusion functioning as exclusion: new students entering the Academy of Music in Sweden. Teachers and Teaching, 21(3), 277-288. doi: 10.1080/13540602.2014.953822

Peñalba, A. (2017). La defensa de la educación musical desde las neurociencias. Revista Electrónica Complutense de Investigación en Educación Musical, 14, 109-127. doi: 10.5209/RECIEM.54814

Power, C. N. (1997). Aprender: ¿medio o fin? Una ojeada al Informe Delors y a sus consecuencias para la reforma educativa. Perspectivas, 27(2), 203-215.

Rickson, D. y Warren, P. (2018). Music for All: Including young people with intellectual disability in a university environment. Journal of Intellectual Disabilities, 22(3), 279-293. doi: 10.1177/1744629517701860

Romero-Hernández, M. F. y Urrego-González, S. (2016). Inclusión de personas con discapacidad sensorial (ciegos y sordos) en los programas de formación musical universitaria en la ciudad de Bogotá, D.C. Uni-Pluri/versidad, 16(2), 27-40. Recuperado de https://bit.ly/2IktTc5

Ruddock, E. (2018). On being musical: Education towards inclusion. Educational Philosophy and Theory, 50(5), 489-498. doi: 10.1080/00131857.2016.1198248

Spitzer, M. (2005). Aprendizaje: neurociencia y la escuela de la vida. Barcelona: Omega

Tawil, S. y Cougoureux, M. (2013). Revisiting Learning: The treasure within - Assessing the influence of the 1996 Delors report. UNESCO Education Research and Foresight, ERF Occasional Papers, 4,1-10. Recuperado de https://bit.ly/2XbsXLm

Terrén, E. (1999). Educación y Modernidad. A Coruña: Universidade da Coruña.

Timoneda, C. (1999). Cognición, emoción y conducta: Modelo humanista-estratégico. Una propuesta de diagnóstico e intervención psicopedagógica basada en y desde la práctica. Revista de Investigación Educativa, 17(2), 515-520. Recuperado de https://bit.ly/2JgvGiz.

UNESCO (2011). The hidden crisis: Armed conflict and education. EFA Global Monitoring Report 2011. París: UNESCO.

UNESCO (2014). Declaración Aichi-Nagoya sobre educación para el desarrollo sostenible. París: UNESCO.

UNESCO (2014a). Teaching and Learning: Achieving quality for all. EFA Global Monitoring Report 2013-2014. París: UNES$\mathrm{CO}$.

UNESCO (2015). Replantear la educación. ¿hacia un bien común mundial? París: UNESCO.

Valcarce-Fernández, M. (2011). De la escuela integradora a la escuela inclusiva. Innovación Educativa, 21, 119-131. Recuperado https://bit.ly/2L6Zh03

Vargas, S. (2010). Aprender enseñando. Nuevas metodologías en el área de Expresión gráfica. Granada: Godel.

Winocur, R. (2007). Nuevas tecnologías y usuarios. La apropiación de las TIC en la vida cotidiana. Telos: Cuadernos de Comunicación e Innovación, 73, 109-117. Recuperado de https://bit.ly/2LH6bZt

Wong, M. W. I. y Chik, M. P. Y. (2016). Teaching students with special educational needs in inclusive music classrooms: experiences of music teachers in Hong Kong primary schools. Music Education Research, 18(2), 195-207. doi: $10.1080 / 14613808.2015 .1044509$ 